\title{
A Model for Successful Professional Learning Communities to Meet the Requirement of Vietnam Education Reform
}

\author{
Pham Thi Thanh Hai ${ }^{1}$, Doan Nguyet Linh ${ }^{1, *}$, Tatsuya Kusakabe ${ }^{2}$ \\ ${ }^{I}$ VNU University of Education, 144 Xuan Thuy, Cau Giay, Hanoi, Vietnam \\ ${ }^{2}$ Hiroshima University, Japan \\ Received 23 November 2021 \\ Revised 30 November 2021; Accepted 09 December 2021
}

\begin{abstract}
Teachers working in rural areas need professional and teaching skills support. This study was conducted at the Lower Secondary School in Hanoi, Vietnam. This research introduces the policy of Professional Learning Communities to the teachers and it's a practice at school. This paper shows a model to implement policies regarding the professional development of teachers at school. The results show that the school runs a good model of professional learning communities such as directing the development and implementation of school education plans and professional training activities. Professional Learning Communities is the target of the teachers at school developing teaching profession.
\end{abstract}

Keywords: Teachers, policy, Secondary school, lesson study, professional learning communities.

\section{Introduction}

Teaching must be respected as a profession as in the recommendation of UNESCO. This is a form of public service requires teachers to specialize in knowledge and professional skills, gained and accumulated through earnest and continuous research; it also requires gifted individuals and a collective responsibility for education and students' duty. The development of professional identity equivalent to the process of becoming a teacher, including the understanding of education, professional

\footnotetext{
* Corresponding author.

E-mail address: haiphamtt@vnu.edu.vn

https://doi.org/10.25073/2588-1159/vnuer.4612
}

training, and themself in educational practice. This process enables future educators to become teachers with the appropriate activities in profession and practice and are willing to take responsibility for their actions; in other words, teachers have the ability to do everything as a well-experienced person in education (T. Dam, Blom, 2006) [1].

In Vietnam, the Fundamental and Comprehensive Education Reform (FCER) was adopted, which aimed for national education to meet "the requirements of industrialization, modernization, and international integration in a socialist-oriented market economy" (Central Steering Committee, 2013) [2]. At its core, the FCER advocates for learning that focuses more on competency of learners rather 
than contents, in general education. It aims to improve students' cognitive and non-cognitive skills, critical and creative thinking, abilities to apply knowledge from multiple areas in problem solving, teamwork, and communication skills.

Professional development plays an important role in improving student learning. Teachers need to conduct professional activities based on lesson study; Periodically participate in professional activities to build illustrated lessons, organize teaching, analyze and draw lessons learned based on the analysis of students' learning activities (N. X. Thanh, 2020) [3].

Professional learning communities (PCLs) have become one of the most discussed ideas in education today. Many K-12 schools are working to become PLCs in the hope that student learning will improve when adults commit themselves to talking collaboratively about teaching and learning and then take action that will improve student learning and achievement (Thompson, Gregg and Niska, 2004) [4].

This study was conducted in the context of Vietnam's comprehensive educational reform. The professional learning community in Vietnam is receiving attention from the policy promulgation and implementation stage to ensure sustainability for teachers to improve their professional capacity.

\section{Literature Review}

To meet the requirements of reforming the general education program, it is necessary to fundamentally change the number of teachers and their professional quality (Lam, 2019) [5]. A combination of studies on the transition to professional teaching shows that class management, discipline, motivating students, resolving individual differences, evaluation, parental relationships, class organization, lack of resources and students' individual problem solving are the most challenging issues. There are challenges related to the curriculum in all areas, including preparation before the lessons and integration during and after the lessons. The reasons for these challenges are internal (e.g., a lack of content knowledge, pedagogical knowledge, and curricular knowledge) and external (e.g., learning demands from students, lack of motivation, lack of instructional or curriculum documents, pressure to adapt to instructional materials for teaching programmes or required experimenting programmes).

There are three core features of professional development activities that have significant, positive effects on teachers' self-education increases in knowledge and skills and changes in classroom practice: i) A focus on content knowledge; ii) Opportunities for active learning; and iii) Coherence with other learning activities (M. S. Garet, 2001) [6]. The profession of teachers is a particular profession and the results directly affect the student's personality. Teachers' training colleges provide professional knowledge and skills for teachers' students. After graduation, each teacher needs to continuously develop his/her professional skills through self-study, formal training, learning. There are many evidences on the effects of teacher continuing professional development on pupil attainment. McKinsey's report "How the world's best-performing school systems come out on top" provides sample evidence to suggest that the quality of teachers is fundamental to the performance of students (Barber, Mourshed, 2007) [7]. From a professional development perspective, traditional professional development activities fall short of helping teachers learn how to teach for understanding. As these kinds of changes in roles are at stake, traditional ways of learning characterized by the transmission of knowledge are bound to miss the mark. Instead, teachers have to acquire competencies that help them fulfil this new role (Kwakman, 2003) [8].

Professional learning communities may have various interpretations in different contexts, but there appears to be broad international consensus that professional learning communities suggest a group of people sharing and critically interrogating their practice in an ongoing, reflective, collaborative, inclusive, learning-oriented, growth-promoting way (Mitchell, Sackney, 2000) [9]. The goal of their actions is to enhance their eff ectiveness 
as professionals for the students' benefit; thus, this arrangement may also be termed communities of continuous inquiry and improvement (Stoll, Bolam, McMahon, Wallace, Thomas, 2006) [10].

The PLCs model has now reached a critical juncture, which is well known to those who have witnessed the fate of other well-intentioned school reform efforts. Most people are interested in PLCs because they offer the hope of making college a more holistic, integrated learning experience for students. People use this term to describe every imaginable combination of individuals with an interest in education, which includes the three central points of ensuring that students learn, maintaining a culture of collaboration, and focusing on results (Supovitz, Christman, 2005) [11].

International evidence suggests that the progress of educational reform depends on teachers' individual and collective capacity and its link with the school-wide capacity for promoting pupils' learning (Stoll et al., 2006) [10].

In Vietnam, a number of studies have addressed the issue of professional development and teacher training in the context of education reform. The ministerial-level education science study "Innovating Teacher Training in the Process of Industrialization, Modernization and International Integration", conducted from 2011 to 2014, has evaluated the current status of and proposed solutions for training teachers. Dung et al., (2015) propose developing a pedagogical curriculum based on a vocational orientation for students in pedagogic schools. The decisive role of the teacher and above all pedagogical schools - which are the "cradle" of training future teachers, have a large impact on the willingness of the teachers involved in comprehensive education reform [12].

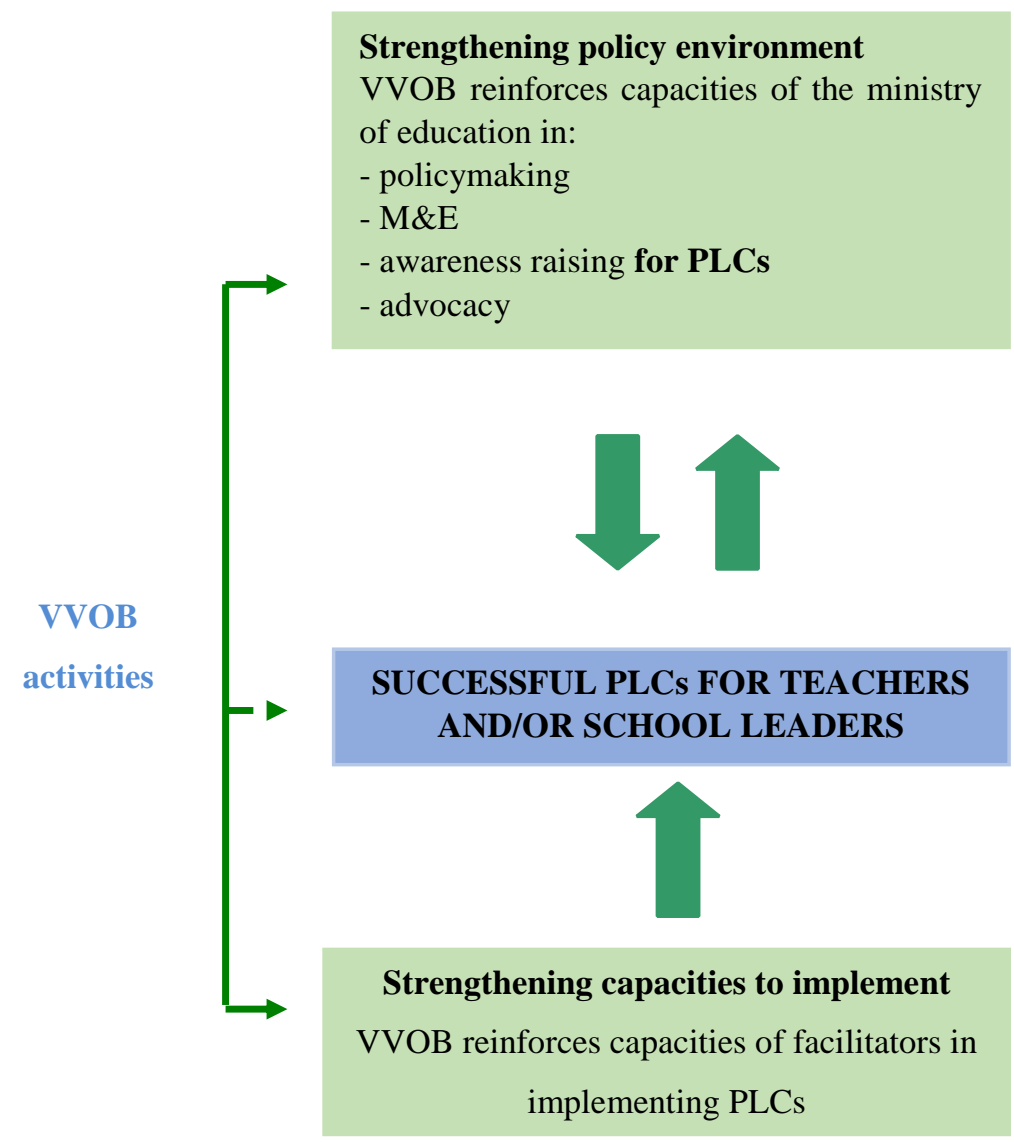

Figure 1. VVOB's model for successful PCLs (VVOB Technical Brief No.2). 
In a study of the career adaptability of postgraduates, it was also asserted that the graduation process of entering the profession is "a complicated transition, a turning point, partly reflecting the process of being trained in pedagogical schools" (Dung, Thuan, 2017) [13]. Putting Sustainable Development Goal 4 into practice: Professional Learning Communities in Education describers how professional learning communities for quality education, as they play an important role in the professional development and motivation of teachers and school leaders. The experiences of VVOB demonstrate how reinforcing the capacities of national and local education authorities to establish and support PLCs is of crucial importance to the success of these communities. (VVOB, education for development) [14].

VVOB's experience shows that PCLs should bridge the gaps between theory, policy and practice; focus on practice, i.e. on the real problems faced by school leaders and teachers; provide opportunities to participants to break out of isolation; create a forum to share materials, data, and tools; are a cost-effective model of professional development; contribute to job satisfaction and motivation.

Currently, there are still few studies on the establishment of the professional development of teachers with regard to the PLCs model in Vietnam. This research was conducted to provide more evidence about the real situation of PLCs and the first results of the application of the PLCs to Nguyen Truc Lower Secondary School in Hatay District in Hanoi. The research results will positively contribute to policy adjustments for general education and particularly teachers in the context of implementing basic and comprehensive reforms of education and training [15].

\section{Research Methods}

\subsection{Methodology}

The research was based on qualitative method, including interviews with policy-makers, educational departments, and teachers. The research is designed based on VVOB's model for successful PLCs (policy making, successful PCLs for teachers and/or school leaders). Content analysis (Anol Bhattacherrjee, 2012) [16] is used in this research which organizes the analysis steps into a 5-stage model: i) Convert recording states to text; ii) Convert raw data into condensed manuscript; iii) Convert the condensed manuscript into preliminary subheadings; iv) Use preliminary subheadings to create encryption protocols; and v) Analysis of encryption protocols for interpretation of content of interest (Schilling, 2006) [17]. By this model, the analysis content shows that PLCs make close between theory, policy and practice; provide opportunities to teachers to create a forum to share materials, data, and tools; are a cost-effective model of professional development; contribute to job satisfaction and motivation.

This research aims to investigate 2 issues: i) How the guideline for PLCs issued by MOET to the teachers is implemented well at school? And ii) Is PLCs a successful model for teachers at school? MOET has issued the guideline No. 5555 (dated 2014) to guide the renewal of professional development for teachers in schools. One of the highlights of this policy is to guide teachers in analyzing and lessons learnt. The lesson analysis can be implemented based on the 3 following specific contents: i) Planning and teaching materials; ii) Organize learning activities for students; and iii) Students' activities.

\subsection{Samples and Settings}

There are 5 policy makers, 1 principal, 2 head master teachers and 5 teachers were interviewed by the semi structured questionnaire. This research was implemented in Hanoi at N. Truc Lower Secondary School, where there are 60 teachers and 688 students in 18 classes. This school is in a rural area, where most teachers are women. The teachers who participated in the survey mostly were formally educated and fully trained to meet the formal requirements, and $67 \%$ of the teachers have completed training beyond the formal 
requirements. Therefore, it is clear that the teachers' qualifications are quite standardized and equal at the professional level; these teachers are also equipped with professional experience and knowledge from professional training courses.

\section{Findings and Discussion}

\subsection{The Policy about Professional Learning Communities in Vietnamese Education System Reform}

i) Vietnamese education system reform

Education is considered a top national priority policy in Vietnam. This view is expressed throughout the development orientation of the country: Science and technology, education and training are top national policies; Investment in education is investment in development. Education has always been a cornerstone of national development, as the Vietnamese government reserves nearly 20 percent of public expenditures for education. However, in the era of globalization, there are concerns that the Vietnamese education system falls short to equip its population with necessary skills in a more competitive economy.

Education in Vietnam is arranged on a national level by MOET. The education levels and training levels of the national education system include: i) Pre-school education includes kindergarten and pre-primary education; ii) General education includes primary education, lower secondary education and upper secondary education; iii) Vocational training for elementary, intermediate and college levels; and iv) Higher education offers undergraduate, master and doctoral degrees. The qualification system has been divided into 8 levels: Level 1 - Elementary Level I; Level 2 - Elementary level II, Level 3 - Elementary level III, Level 4 - Intermediate level; Level 5 - College; Level 6 - University; Level 7 - Master; Level 8 - PhD (Vietnam Ministerial 1982/QD-TTg, dated 2016).

Teacher education institutions are subjected to state management by the MOET. Standard academic requirements for high school teachers are setted to be from the pedagogy graduate (colleges of 3-4 years - from level 5 and higher based on the National qualification system). Currently, the pre service training teachers are provided by pedagogical universities. Professional development after graduation (in service) is often less interested. To combine initial training with actual continuous training is to improve teaching capacity and professional development of the teachers has not been paid attention. In order to teach according to competence, teachers themselves must have basic skills in teaching and in education; Therefore, fostering capacity for teachers, especially primary teachers, is an important task (Hoa, 2018) [18].

Teachers are required to attend annual regular professional development training in Vietnam. The objectives of these training courses are to help: i) Teachers update their knowledge about politics, economy - society, fostering political qualities, professional ethics, developing teaching capacity and other competencies required by the professional standards of teachers, requiring the academic year, grade level, local educational development requirements, requirements for innovation and improving the quality of education; ii) Developing teachers' self-study and self-fostering capacity; capacity of self-assessment of effectiveness of continuously training; capacity of organizing and managing self-study and self-training activities of teachers, the department of education and training. The regular training program for high school teachers consists of 3 modules. MOET is in charge of instructing the first module, and regularly updating the 3 rd module. Departments of Education and Training (provincial level) are in charge of instructing the 2nd module. However, the realization of such a reform depends almost exclusively on the preparedness of teachers to adopt the new pedagogical models. Indeed, one of the principles of the FCER stresses that teachers should be more professional and be ready to adapt to different, constantly changing contexts. Hence, teachers 
are considered the core of the reform process. Teacher training and support activities focus on greater interaction between professionals, reciprocity, hands-on mentorships, and coaching and on-time advice to teachers.

Despite positive results in education of Vietnamese teachers and students, there is a lack of high quality, responsive, and continuous onsite professional development for teachers. One of the biggest challenges is better coordination among all involved teacher education to meet new demands. To address these challenges, the National Teacher Education Program, conceived by MOET, has developed a comprehensive strategy for teacher education reform. It is expected to facilitate necessary changes to meet training objectives in consideration of teachers' needs;

ii) Vietnamese Education Policy about Professional Learning Communities

MOET has issued Circular 20/2018/ TT-BGDDT on stipulating professional standards for general education teachers, including 5 standards. In which, Standard 2 stipulates professional development. This standard requires teachers to have professional knowledge and expertise; regularly update and improve professional and professional capacity to meet educational innovation requirements. This standard includes 5 criteria that are evaluated at 3 levels.

Table. Standard 2.

Teachers' professional development

\begin{tabular}{|l|l|}
\hline No & Criteria \\
\hline 1 & Personal professional development \\
\hline 2 & $\begin{array}{l}\text { Develop a teaching and educational plan } \\
\text { in the direction of developing students' } \\
\text { quality and capacity }\end{array}$ \\
\hline 3 & $\begin{array}{l}\text { Using teaching and educational methods } \\
\text { in the direction of developing students' } \\
\text { qualities and abilities }\end{array}$ \\
\hline 4 & $\begin{array}{l}\text { Examination and assessment in the } \\
\text { direction of developing students' qualities } \\
\text { and abilities }\end{array}$ \\
\hline 5 & Student counseling and support \\
\hline
\end{tabular}

Vietnam has a plan to reform general education, and at the same time, promulgate a number of policies related to the teacher profession. There are several policies that guide professional practice, such as: Official Dispatch 5512/BGDĐT - GDTrH dated December 18, 2020 explicitly states in Section II.2. developing the education plan of the expert group that the specialized groups construct the Education Plan of the Expert Group, including the subject teaching plan and education activity plan.

\subsection{Successful Professional Learning Communities for Teachers}

i) The implementation of professional development for teachers in schools.

Planning and teaching materials

The results show that "The level of clarity in the objectives, content, planning and results of each learning task" is the highest regarded criteria when considering the school's teaching plans and materials (interview, 2020). Vietnam possesses a suitability policy system for instructing teaching activities at schools. In fact, Vietnamese government uses only one general education curriculum and one textbooks system so that the training for teachers is very clear. The instructional documents for each subject including the objectives, regulations, content, teaching methodologies and classroom assessment techniques are provided by the MOET. This statement is very similar to the study of Developing teacher training programs meet the requirements of reforming general education in Vietnam (Tu, Hanh, 2017) [19].

Organization of learning activities

The results show that responded highest on "How lively and interesting are the transition methods to learning tasks towards students" (interview, 2020). Students' performance at school is proportional to the teachers' teaching basis. The professionalization from teachers can be shown in the way the lessons are planned; the ability to detect students' difficulties during classes and to come up with an appropriate solution; and the ability to use assessment tools effectively in order to encourage students' creativity. This result is a clear evidence of 
the relationship between the students' learning process and the teachers' professionalization (Desimone, 2009) [20].

Students' activities

The student's activity that got the highest preference from the teachers is "Ability to receive and readiness to carry out learning tasks from all students in class" (interview, 2019). Teachers who are passionate about their profession and always looking for a suitable teaching method will be able to encourage students' interest in learning. This is pointed out that teachers' emotions towards teaching are influential towards the teaching performance as well as professional skills or a teaching framework. Teachers will have positive emotions when teaching and experience student progress (Chen, 2006) [21];

ii) Successful Professional Learning Communities for teachers at school

According to VVOB's model for successful PLCs, there needs to be a policy for professional development (policymaking), regular M\&E and clear evaluation criteria and timely recommendations (awareness raising).

To implement the MOET guideline (MOET, 2014) to guide the renewal of professional development for teachers in schools, The Department of Education and Training has directed the plans for the 2018-2019 school year: promoting the teaching of problem solving, applying practical methods in subjects, ensuring balance between knowledge transitions, orienting students' attitudes and behaviours, strengthening practical applications, integrating subjects, and actively applying information technology according to the curriculum (Hatay, 2018) [22]

The school implements directed professional development and termly evaluates teachers (school year report, 2019). Regarding to Planning and teaching materials, " $100 \%$ of teachers have implemented integrated teaching skills and values in certain subjects and creative experiential activities. The majority of integrated teaching hours are highly effective". (interview, 2020). At the same time, organizing learning activities for students is always put on the central issue in the professional meeting and training to the teachers (interview, 2020). In the same way, Stoll et al., (2006) pointed out there are some identities of PCLs, including collective teamwork, in which leadership and responsibility for student learning is widely shared, with a focus on finding understanding, reflection and dialogue between teachers, between professional teams that emphasize improving student learning, shared values and norms, and the development of shared practices and feedback [23].

In school, professional training activities are held every 2 weeks. Professional training activities should be updated with new notices and additional guidelines regarding organizing class observations and discussing and improving the quality of teaching - so the learning is based on the teachers' needs. Each team has held 2 professional training seminars/semester (interview, 2020).

Professional learning communities are maintained in various forms. Nam et al., (2011) presents models of teacher professional development and the implementation of these models in professional development activities. Professional learning in training courses helps teachers to learn from each other and develop professionally [24]. Simillarly, Ngoc, Thanh (2019) believes that forming and developing specialized magazine reading clubs - a form of professional learning community, Professional development activities for teachers [25].

Teachers determined that one of the criteria is that the school is a learning community based on the lesson study model. In the annual plan of the school year, there pointed out the activities to promote teachers' scientific research, to exchange experiences (interview, 2020). On the other hands, Schools must break away from the administrative model and adopt a new model that allows them to function as learning institutions if they want to be more effective. School sould be an learning institution as "professional learning communities" because "communities" place more emphasis on relationships, shared ideals, learned from each other and a school culture - all factors important 
for school improvement. The challenge for educators is to create a committed community - a professional learning community.

\section{Conclusion}

Vietnam is implementing a comprehensive reform of the basic education system through the reform of the curriculums and textbooks of the general educational system. Professional development that responds to educational innovation is a mandatory requirement. This research introduces the model for VVOB's model for successful PCLs which is applied to Vietnam to meet the educational reform. The paper focused on the implementation of professional development policies towards PCLs. The results show that the school runs a good model of professional learning communities such as directing the development and implementation of school education plans and professional training activities. The teachers acknowledge that the role of lesson study in learning communities in the School is useful not only for the teachers but also for the students in learning groups. Professional Learning Communities is the target of the teachers at school developing teaching profession.

\section{Acknowledgements}

This research is funded by Vietnam National Foundation for Science and Technology Development (NAFOSTED) under grant number 503.01-2020.03

\section{References}

[1] G. T. Dam, S. Blom, Learning Through Participation, The Potential of School-based Teacher Education for Developing a Professional Identity, Teaching and Teacher Education, Vol. 22, No. 6, 2006, pp. 647-660, https://doi.org/10.1016/j.tate.2006.03.003.

[2] Resolution No. 29-NQ/TW Dated November 4, 2013 of the $8^{\text {th }}$ Central Conference of the XI Term on Fundamental and Comprehensive Reform of Education and Training (in Vietnamese).
[3] N. X. Thanh, Innovation of Teaching Contents and Methods in New General Education Program, Proceedings of Scientific Conference: Innovation of Education and Training for Sustainable Development Goal, 2020, pp. 20-28.

[4] S. C. Thompson, Gregg, Larry; Niska, M. John, Professional Learning Communities, Leadership, and Student Learning, RMLE Online: Research in Middle Level Education, Vol. 28, No. 1, 2004, pp. 1-15.

[5] D. B. Lam, Innovation of High School Administration Synchronize with Innovation of General Education Program, Proceedings of the First International Conference on Teachers Training Innovation, 2019, pp. 425-431.

[6] M. S. Garet, A. C. Porter, L. Desimone, B. S. F. Birman, K. S. Yoon, What Makes Professional Development Effective? Result from a National Sample of Teachers, American Educational Research Journal, First Publish January 1, 2001.

[7] M. Barber, M. Mourshed, How the World's Best Performing School Systems Come Out on Top, London: McKinsey and Company, 2007.

[8] K. Kwakman, Factors Affecting Teachers' Participation in Professional Learning Activities, Teaching and Teacher Education, Vol. 19, No. 2, 2003, pp. 149-170, https://doi.org/10.1016/S0742051X(02)00101-4.

[9] C. Mitchell, L. Sackney, Profound Improvement: Building Capacity for a Learning Community, Lisse, The Netherlands: Swets and Zeitlinger, 2000.

[10] L. Stoll, R. Bolam, A. McMahon, M. Wallace, S. Thomas, Professional Learning Communities: A Review of the Literature, Journal Of Educational Change, Vol. 7, No. 4, 2006, pp. 221-258, https://doi.org/10.1007/s10833-006-0001-8.

[11] J. Supovitz, J. B. Christman, Small Learning Communities that Actually Learn: Lessons for School Leaders, Phi Delta Kappan, Vol. 86, No. 9, 2005, pp. 649-651, https://doi.org/Article.

[12] N. T. K. Dung et al., Pedagogical Training in the Direction of Vocational Skills for Students in Pedagogical Universities, Publisher of Pedagogical University, 2015 (in Vietnamese).

[13] N. T. K. Dung, D. T. Thuan, Criteria for Assessing Career Adaptability of Undergraduated Student, Hanoi University of Science Journal of Science, Vol. 1A, 2017, pp. 200-206 (in Vietnamese).

[14] VVOB Technical Brief - Professional Learning Communities in Education | VVOB vzw Vietnam, Vietnam.vvob.be, Retrieved 1 December 2021, from https://vietnam.vvob.be/en/resources/vvobtechnical-brief-professional-learningcommunities-education/, 2021 (accessed on: November $\left.23^{\text {rd }}, 2021\right)$. 
[15] Report Assessing the Performance of the 2018, 2019, 2020 School Year, Nguyen Truc Secondary School.

[16] A. Bhattacherrjee, Social Science Research: Principles, Methods, and Practices, Published Under the Creative Commons Attribution-non Commercial-shareAlike 3.0 Unported License, 2012.

[17] J. Schilling, On the Pragmatics of Qualitative Assessment: Designing the Process for Content Analysis, European Journal of Psychological Assessment, Vol. 22, No. 1, 2006, pp. 28-37, https://doi.org/10.1027/1015-5759.22.1.28.

[18] D. T. Hoa, In Service Training of Teaching Capacity for Primary Teachers Towards Developing Student Capacity, Educational Journal, Vol. 2, No. 3, 2018 , pp. 17-20 (in Vietnamese).

[19] H. T. Tu, N. T. Hanh, Develop Teacher Training Programs to Meet the Requirements of Vietnam General Education Reform, VNU Journal of Science: Education Research, Vol. 33, No. 2, 2017, pp. 1-9, https://doi.org/10.25073/2588-1159/vnuer.4090.

[20] L. A. Desimone, Improving Impact Studies of Teachers' Professional Development: Toward Better
Conceptualizations and Measures, Educational Researcher, Vol. 38, 2009, pp. 181-200, https://doi.org/10.3102/0013189X08331140.

[21] J. Chen, Understanding Teacher Emotions: The Development of a Teacher Emotion Inventory, Teaching and Teacher Education, Vol. 55, 2016, pp. 66-77.

[22] REPORT Assessing the Performance of the 2018, 2019, 2020 School Year and the Key Directions and Tasks for the 2017-2018, Department of Education in Thanh Oai, Hatay District, Hanoi, Vietnam.

[23] L. Stoll, R. Bolam, A. McMahon, M. Wallace, S. Thomas, Professional Learning Communities: A Review of the Literature, Journal Of Educational Change, Vol. 7, No. 4, 2006, pp. 221-258, https://doi.org/10.1007/s10833-006-0001-8.

[24] N. T. H. Nam et al., Theoretical Issues and Practice Experience in Professional Development for High School Teachers, Journal of Science 2011, Vol. 18a, 2011, pp. 128-138.

[25] N. T. B. Ngoc, T. M. Thanh, Special Magazine Reading Club as Professional Development Activities for Teachers, TNU Journal of Science and Technology, Vol. 209, 16, 2019, pp. 93-100. 